\title{
Studying pregnancy outcome in twin gestation in developing world.
}

\author{
${ }^{1}$ Shugufta Yasmeen Rather (MD), ${ }^{2}$ Rizwana Habib (MD), ${ }^{3}$ Preeti Sharma \\ (MBBS) \\ ${ }^{1}$ Lecturer Postgraduate Department of Obstetrics and Gynecology Government Medical College Srinagar \\ Kashmir INDIA 190008 \\ ${ }^{2}$ Associate professor Postgraduate Department of Obstetrics and Gynecology Government Medical College \\ Srinagar Kashmir INDIA 190008 \\ ${ }^{3}$ Postgraduate student Postgraduate Department of Obstetrics and Gynecology Government Medical College \\ Srinagar Kashmir INDIA 190008
}

\begin{abstract}
:
Objective: To study the maternal and neonatal outcome in multifetal gestation in a tertiary care centre.

Method: A retrospective observational analysis of 100 twin pregnancies admitted and managed at our centre was done. Patients were studied for any adverse antenatal complications, mode of delivery and pregnancy outcome both maternal and perinatal.

Results: Most of patients with twin pregnancy (34\%) were primigravidas. $70 \%$ patients were admitted between the pregnancies of $28-36$ weeks duration with preterm labor (68\%) as the commonest indication for admission to hospital. Anemia (63\%), gestational hypertension (28\%), premature rupture of membranes (24\%), IntraUterine Death of one fetus (12\%) and intra uterine growth retardation (10\%) were the antenatal complications observed. Out of the 100 patients 40 (40\%) delivered by vaginal route whereas 60 (60\%) had to undergo cesarean section. Malpresentation was the commonest indication (50\%) for cesarean section. The 100 women of twin pregnancy gave birth to 188 live-born babies, 12 stillborn (intrauterine death of one fetus) and 28 (14.8\%) died by the end of one week due to complications related to prematurity: hyaline membrane disease, hyperbilirubinemia.

Conclusion: The risks of pregnancy related complications in twin gestation are definitely more than a singleton pregnancy. Early detection and proper management of twin pregnancies can reduce the complication rates thereby improving maternal and neonatal outcome.
\end{abstract}

Key words: Twin pregnancy, maternal morbidity and mortality, neonatal morbidity and mortality.

\section{Introduction}

Multiple gestation currently account for $3 \%$ of all pregnancies ${ }^{1}$. Compared to singleton pregnancies the perinatal mortality, morbidity and long term neuro-developmental disability are increased $5-10$ fold in twin pregnancies ${ }^{2}$. Women with more than one fetus are $2-4$ times more likely to experience complications of pregnancy ${ }^{3}$. This retrospective observational study of 100 women with twin pregnancy was conducted to evaluate pregnancy related complications in the mother and neonatal outcome in a developing country.

\section{Methods}

This retrospective study was conducted at Government Lalla Ded Hospital, the lone tertiary care maternity hospital in Kashmir province of J\&K State of India. 100 consecutive women with twin pregnancies that were admitted either as registered antenatal patients or referral cases in the year 2013 were studied. Individual patient parameters like age, parity, duration of gestation, physical examination, mode of delivery, antepartum, intrapartum and postpartum complications were tabulated. Neonatal morbidity and mortality in the first week were also noted. Results of routine and specialized investigations and ultrasonography were recorded. Data thus obtained was analyzed and results studied.

\section{Results}

Majority of patients studied were in the age group of $26-35$ years (mean age -29 years) (table 2 ). $34 \%$ patients were primigravidas and $28 \%$ were paral (table1). Most of the women (82\%) at the time of admission were in the third trimester (table 3 ) with $70 \%$ patients in the $28-36$ weeks gestational age. 


\section{Parity}

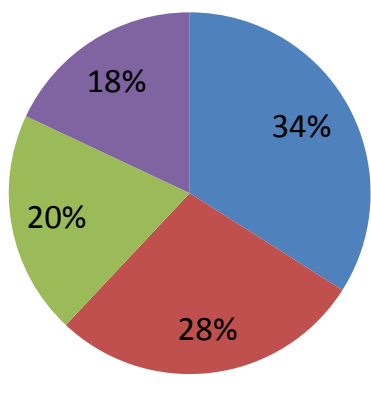

$\square \quad \square \quad 1 \quad 2 \square 3$ or more

Chart 1: Distribution of women according to parity

\begin{tabular}{|c|c|}
\hline Patient Age $(\mathrm{yrs})$ & Number \\
\hline Less than 20 & 0 \\
\hline $21-25$ & 22 \\
\hline $26-30$ & 28 \\
\hline $31-35$ & 30 \\
\hline 36 and above & 20 \\
\hline
\end{tabular}

Table 2: Distribution of women according to age

\begin{tabular}{|c|c|}
\hline Gestational Age & No \\
\hline Less than 24 weeks & 2 \\
\hline $25-28$ & 16 \\
\hline $29-36$ & 70 \\
\hline More than 36 & 12 \\
\hline
\end{tabular}

Table 3: Distribution of women according to period of gestation at admission

\begin{tabular}{|l|c|}
\hline Outcome & Number \\
\hline Premature Labor & 68 \\
\hline Anemia & 63 \\
\hline Gestational Hypertension & 28 \\
\hline Premature Rupture of Membranes & 24 \\
\hline IUD Of One Fetus & 12 \\
\hline IUGR & 10 \\
\hline Postpartum Hemorrhage & 18 \\
\hline Placenta Previa & 2 \\
\hline Gestational Diabetes Mellitus & 5 \\
\hline Polyhydramnios & 4 \\
\hline Accidental Hemorrhage & 2 \\
\hline No Complication & 26 \\
\hline Maternal Death & Nil \\
\hline
\end{tabular}

\section{Table 4: Maternal outcome}

\begin{tabular}{|l|c|}
\hline APGAR $<7$ at $1 \mathrm{~min}$ & 124 \\
\hline APGAR $>7$ at $10 \mathrm{~min}$ & 76 \\
\hline Admission to NICU & 140 \\
\hline IUD & 12 \\
\hline Neonatal Deaths at $1^{\text {st }}$ week & 28 \\
\hline
\end{tabular}

Table 5 Neonatal outcome 
Pregnancy related complications (table 4) in one form or other were present in $74 \%$ patients at the time of admission. Preterm labor was the most frequently encountered complication seen in $68 \%$ patients, followed by anemia (63\%), gestational hypertension (28\%), premature rupture of membranes (24\%) and Intra uterine growth retardation (10\%). Pregnancy was uneventful in 26 patients. No maternal death was recorded in the study group.

Out of the 100 patients studied, 40 patients delivered vaginally. Majority of them came in established preterm labour in early third trimester. 60 patients had to undergo cesarean section (Table 6). Malpresentation (50\%) was the commonest indication for LSCS, followed by twins with previous scar and acute fetal distress (Table 7)

\begin{tabular}{|l|c|}
\hline Spontaneous & 12 \\
\hline Assisted breech & 24 \\
\hline Instrumental & 4 \\
\hline LSCS & 60 \\
\hline
\end{tabular}

Table 6 Mode of delivery

\section{Indication for C Section in twin pregnancy}

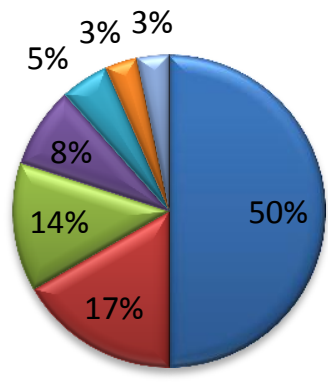

Malpresentation

Q Previous Scar

$\square$ Acute Fetal Distress

GHypertension

$\square$ Non Progression

$\square$ Placenta Previa

\section{Indication for C Section in twin pregnancy}

The 100 women gave birth to 188 live births, 12 were stillborn due to IUD of one or both fetuses and 28 more could not survive more than a week due to complications (table 5). The commonest complications seen in the perinatal period were hyaline membrane disease, neonatal sepsis and hyperbilirubinemia. Neonatal morbidity and mortality was inversely related to the gestational age at birth.

\section{Discussion}

Twin pregnancy constitutes a important portion of high risk pregnancies attending any obstetric health care facility. $34 \%$ patients in our study were primigravidas and the highest number of patients was in the age group 31 - 35 years $(30 \%)$ with mean maternal age of 29 years. Similar age incidence was seen by Malik et al Lahore $^{4}$. Women with multiple pregnancy are at increased risk of preterm labour, pre-eclampsia, post-partum hemorrhage and anemia. ${ }^{5-7} 74 \%$ of women with twin pregnancy in our study had one or more than one obstetric complication. Preterm labour and delivery was seen in $68 \%$ of cases followed by anemia in $63 \%$ and gestational hypertension in $28 \%$. IUD of one fetus, postpartum hemorrhage and IUGR were other common complications encountered. Similar incidence of complications was found in a study conducted by Shahela Khateq et al ${ }^{8}$. LSCS was the commonest mode of delivery $(60 \%)$ in our study with malpresentation being the commonest indication (50\%). $70 \%$ patients delivered preterm at a gestation of $28-36$ weeks.

Out of 188 live born babies, 28 died (14.8\%) at the end of first week mostly due to sequel of preterm birth. Prematurity is the leading cause of perinatal mortality in multiple pregnancy as was also revealed by studies of Koram et al ${ }^{9}$ and Ziadeh $\mathrm{S}^{10}$

\section{Conclusion}

Complications associated with higher order pregnancies cannot be prevented but can be detected early and controlled adequately by proper and prompt management. Regular and more frequent antenatal checkup with liberal hospital admission policy for twin pregnancy is essential to reduce adverse pregnancy outcome in such women. 
There is a need for effective implementation of strategies to ascertain the risk factors, incidence and indications for operative deliveries

\section{Bibliography}

[1]. American College of Obstetricians and Gynecologists: Special problems of multiple gestation. Education bulletin No. 253 , 1998.

[2]. Multiple Pregnancy: The Management of Twin and Triplet Pregnancies in the Antenatal Period. NICE Clinical Guidelines, No. 129. National Collaborating Centre for Women's and Children's Health (UK). London: RCOG Press; 2011 Sep.

[3]. Conde-Agudelo A, Belizan JM, Lindmark 0. Maternal morbidity and mortality associated with multiple gestations. Obstet. Gynecol., 2000; 95:899904.

[4]. Malik MS, Rashid U. Complications of Twin gestation. Biomedica 1998; 14: 22 - 26.

[5]. Senat MV, Ancel PY, Bouvier - Colle et al. how does multiple gestation affect maternal morbidity and mortality? Clinical obs gyne $1998 ; 41: 79-83$.

[6]. Coonrod DV, Hickok DE, Zhuk. Risk factors for pre-eclampsia in twin gestation - a population based cohort study. Obs gynae $1995 ; 85: 645-50$.

[7]. Coonmbs CA, Murphy EL, lam RK Jr. Factors associated with postpartum hemorrhage with vaginal birth. Obs GYne 1991; 77: 69 -76 .

[8]. Kahn B, Lumey LH, Zybert PA, Lorenz JM, Cleary-Goldman J, D'Alton ME. Prospective risk of fetal death in singleton twin nd triplet gestation; implications for practice. Obs gyne 2003; 102: 685 - 92.

[9]. . Koram L, Kamdom Moyo J. Fetal risk factors in twin pregnancies, critical analysis of 265 cases. Rev, Fr. Gynecol.Obstet., 1995; 90: $55-62$.

[10]. Ziadeh S. outcome of twin pregnancies in north Jordan. J Obs Gyn 2000; 20: 492 - 94. 